\title{
RHEUMATOID ARTHRITIS OF THE TEMPOROMANDIBULAR JOINTS*
}

\author{
BY \\ JOSEPH J. MARBACH AND HARRY SPIERA \\ From the Departments of Dentistry and Medicine, \\ The Mount Sinai Hospital and Mount Sinai School of Medicine, \\ New York, New York 10029
}

\begin{abstract}
Although temporomandibular-joint involvement by rheumatoid arthritis is well recognized, its incidence is unknown. Russel and Bayles (1941) estimated that the temporomandibular joints became involved in 50 per cent. of patients, Ragan (1949) 4.7 per cent., Markowitz and Gerry (1950) $8 \cdot 7$ per cent., and Einaudi and Viara (1964) $29 \cdot 3$ per cent in 260 rheumatoid arthritics. These variations may be explained by the use of different diagnostic criteria and different populations. The present study describes two patients in whom temporomandibular-joint arthritis is a prominent feature, and our attempts to treat them in a rational manner based upon an understanding of the mechanics of the temporomandibular joints.
\end{abstract}

\section{Case Reports}

Case 1, a 37-year-old woman, complained of progressive elongation of the lower one-third of her face, a change in the relationship of her upper and lower teeth, and difficulty in chewing of 2 years' duration. She had had rheumatoid arthritis for 27 years with typical rheumatoid deformity of the hands, wrists, knees, and shoulders. She had been treated with salicylates and gold salts, and had had multiple synovectomies. The latex fixation test was strongly positive and the erythrocyte sedimentation rate $60 \mathrm{~mm}$./hr (Westergren). Histological examination of tissue removed at the time of orthopaedic surgery showed changes typical of rheumatoid arthritis.

Clinical Examination.-Mandibular movements were co-ordinated but restricted, especially the straight protrusive movement (forward thrust) of the mandibular condyles. The left manibular condyle could not be palpated. The right masseter and temporalis and the left masseter muscles were painful on palpation. The mentalis and depressor labii inferioris muscles appeared lengthened.

*Read in part at the Annual Meeting of the New York Rheumatism Association on April 18, 1967.
Dental Examination.-Only the maxillary and mandibular second molar teeth made contact when the patient brought her teeth together. She stated that before the onset of rheumatoid arthritis her teeth had made normal contact, and this was verified by wear facets on her teeth that evidenced years of contact. An interincisal opening of $2 \mathrm{~mm}$. existed with the molar teeth in contact (Fig. 1). She had difficulty in chewing, and a frontal or labial lisp distorted her speech.

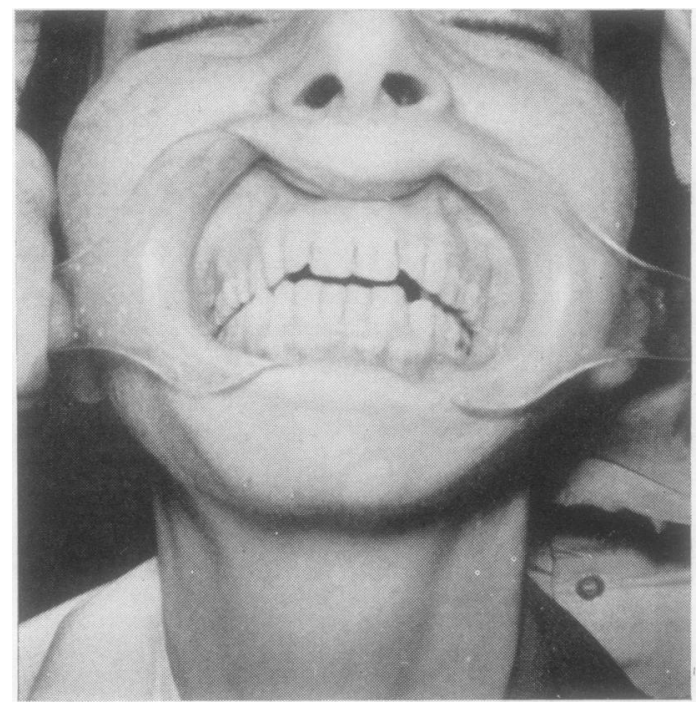

Fig. 1.-Case 1. With the second molar teeth in contact there is an increasing opening anteriorly.

Radiographs.-The left mandibular condyle was flattened on the anterior and superior aspects (Figs $2,3,4,5$, opposite). A round radiolucent area was seen near the superior border of the condylar head. A spur was present on the anterior surface at the site of the tendinous insertion of the lateral pterygoid muscle. The articular eminence of the temporal bone was flattened while the joint space was greatly enlarged. The right 

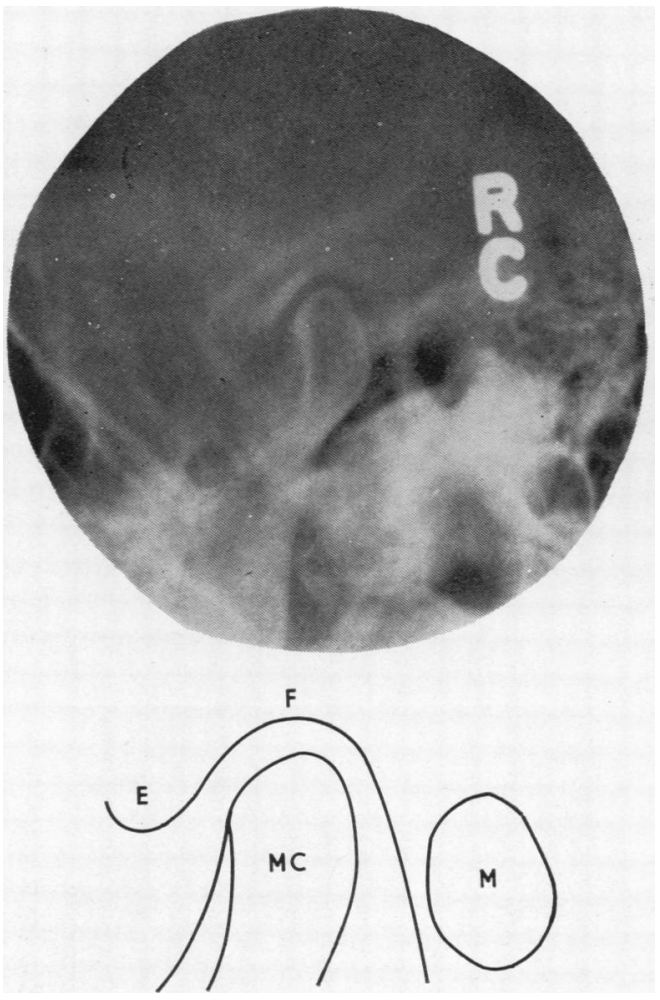

Fig. 2.-Normal right temporomandibular joint in closed position (M) internal auditory canal. (MC) mandibular condyle. (E) articular eminence of temporal bone. (F) glenoid fossa of temporal bone. Note smooth cortical plate with cancellous bone in centre and smooth concave congruous glenoid fossa of temporal bone.

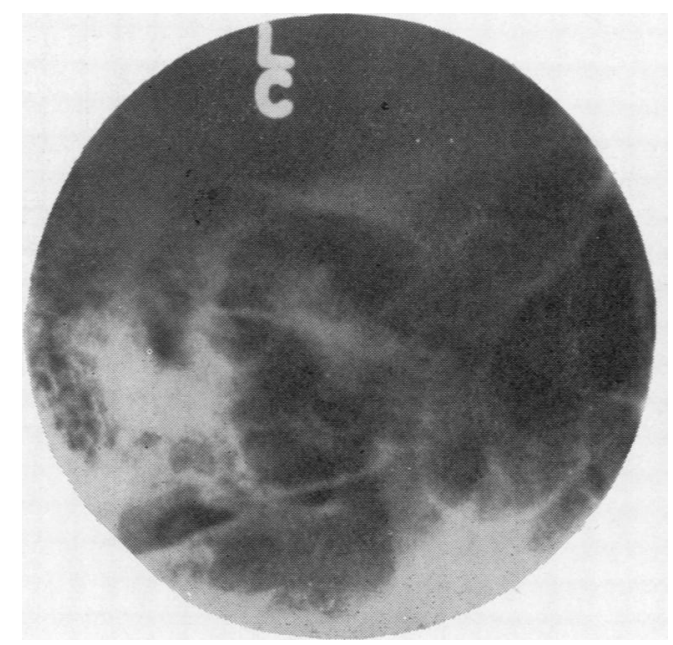

Fig. 4.-Case 1. Left temporomandibular joint in closed position, showing flattening of anterior and superior aspects of mandibular condyle. A radiolucent area is seen near the superior border. A spur is present on the anterior surface. There is a flattening of the glenoid fossa.

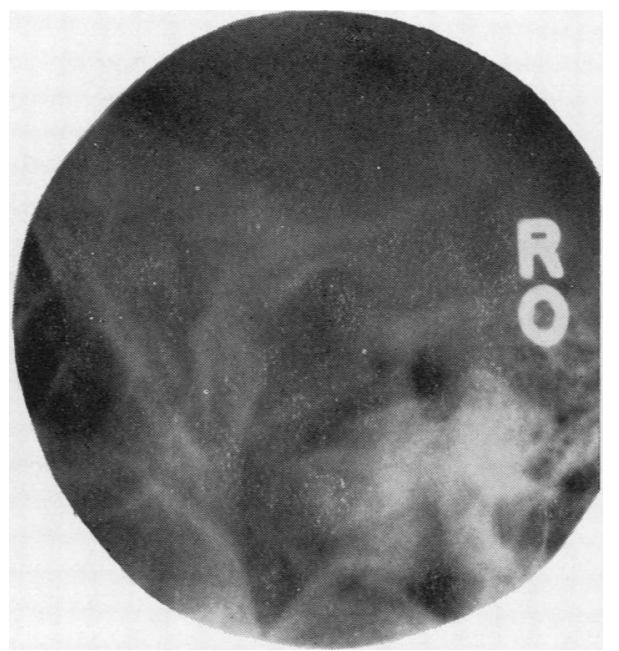
Fig. 3.- Normal right temporomandibular joint in open position.
Note anterior movement of entire condylar head. In the action of opening the condyle first rotates and then translates.

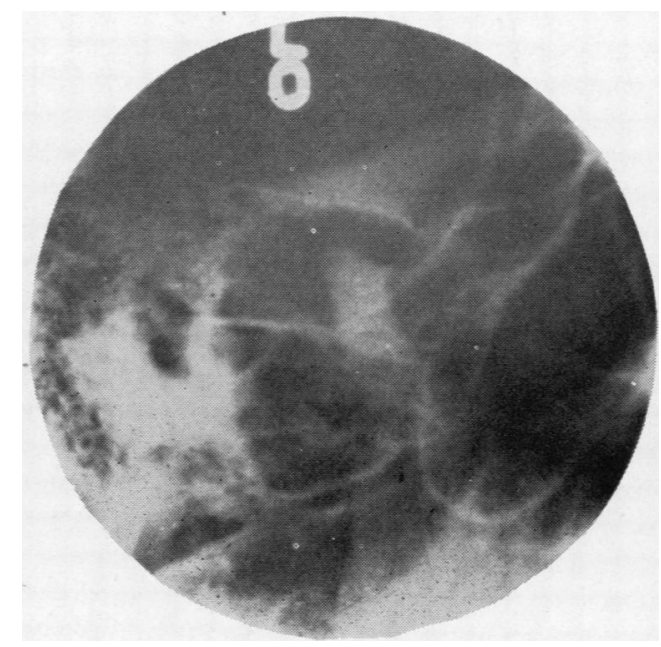

Fig. 5.-Case 1. Left temporomandibular joint in open position. There is little forward movement of the mandibular condyle. 
mandibular condyle was flattened superiorly. Both mandibular condyles showed sclerotic changes.

Treatment.-This comprised therapeutic exercises, reduction in the height of the posterior teeth, and retraining of the tongue. Because of the progressiveness of the patient's rheumatoid arthritis, dental treatment was confined to the reduction of the natural tooth structure of the posterior teeth. Gold crowns were not used because they in turn might have to be ground down. Thermal sensitivity of the teeth was controlled with the use of a desensitizing dentifrice. Stretching exercises increased the mandibular opening from 43 to $49 \mathrm{~mm}$. The straight protrusive movement remained restricted. The patient's speech was improved by retraining tongue movements.*

Case 2, a 31-year-old woman, complained of changes in her bite, elongation of her face, and difficulty in chewing. The onset of polyarthritis involving wrists, knees, and the proximal interphalangeal joints of the hands had occurred 2 years before. At that time the latex fixation test was positive. She had been treated initially with prednisone and then with aspirin with good response.

Physical Examination.-There were bilateral flexion deformities of the elbows and tenderness and swelling at the proximal interphalangeal joints. The erythrocyte sedimentation rate was $16 \mathrm{~mm} . / \mathrm{hr}$ (Westergren), and the latex fixation test for rheumatoid factor was negative.

Clinical Examination.-There was an interincisal opening of $3 \mathrm{~mm}$. with the molar teeth in contact (Fig. 6). Mandibular movements, especially the straight protrusive movement (forward thrust) of the mandibular condyles, were coordinated but restricted. The mentalis and depressor labii inferioris muscles appeared lengthened (Fig. 7).

Radiographs.-There was a flattening of the glenoid fossa and the anterior aspects of the left and right mandibular condyles. The right condyle showed the cortical bone intact (Fig. 8, opposite). The left showed an irregular outline and sclerotic bone.

*It is interesting to note the comments of Goodwill and Steggles (1966) with regard to treatment of the teeth in rheumatoid arthritis of the temporomandibular joints:

"Since this is a progressive process, restoration of occlusion function presents a problem. The best solution seems to be restoration of the occlusion by means of a prosthesis causing as little interference with free mandibular movement as possible; this allows for variations in the relationships of the head of the mandible in the region of the glenoid fossa."

In our opinion, it is important to make clear that the prosthesis should be fixed whenever possible. The patient described by Goodwill and Steggles was an edentulous individual for whom complete dentures were constructed. The shortcomings of removable appliances with their inherent instability, resting on the oral mucous pliances with their inherent instability, resting on the oral mucous When this capacity is decreased as in disease, the success of the When this capacity is decreased as in disease, the success of the
prosthesis is likewise decreased, and it is therefore wise to attempt to restore and maintain all the natural teeth. We also wish to comment on the relationship of the head of the mandible to the glenoid fossa. It should be emphasized that this relationship is governed primarily by the musculature of the joint and not by the teeth. Thus treatment should begin with and concentrate upon the muscles involved before any dental therapy is started.

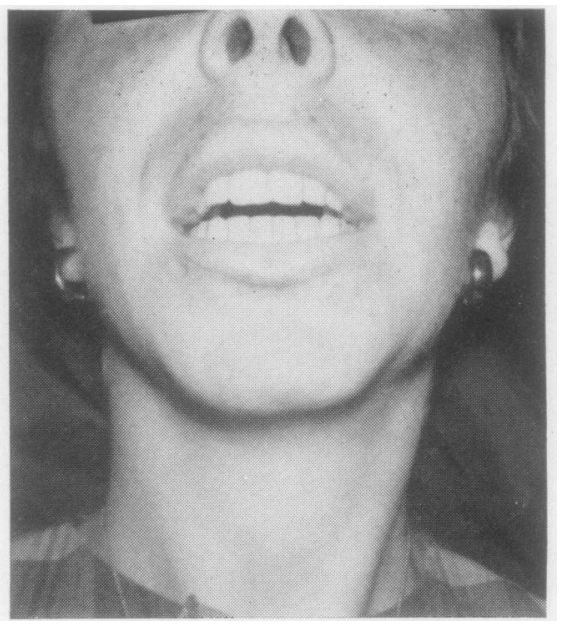

Fig. 6.-Case 2. Increasing opening from second molar forwards.

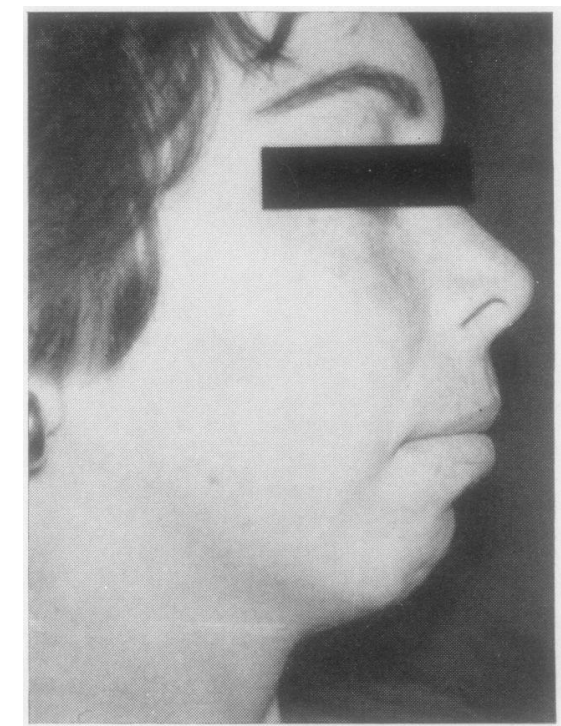

Fig. 7.-Case 2. Upward displacement of soft tissue overlying bony gnathion with lips in contact.

Treatment.-This comprised therapeutic exercises, reduction in the height of the posterior teeth, retraining of the tongue, and orthodontic movement of the upper anterior teeth.

Examination initially and at the second visit revealed a maximum mandibular opening of $33 \mathrm{~mm}$. measured from the incisal edges of the upper and lower central incisor teeth, which was a restricted opening for this patient. Increased mandibular range was achieved with the following exercise:

The patient was first to stretch her mouth open ten times and then to place her fist under her chin and open her mouth three times against the gentle upward pressure 


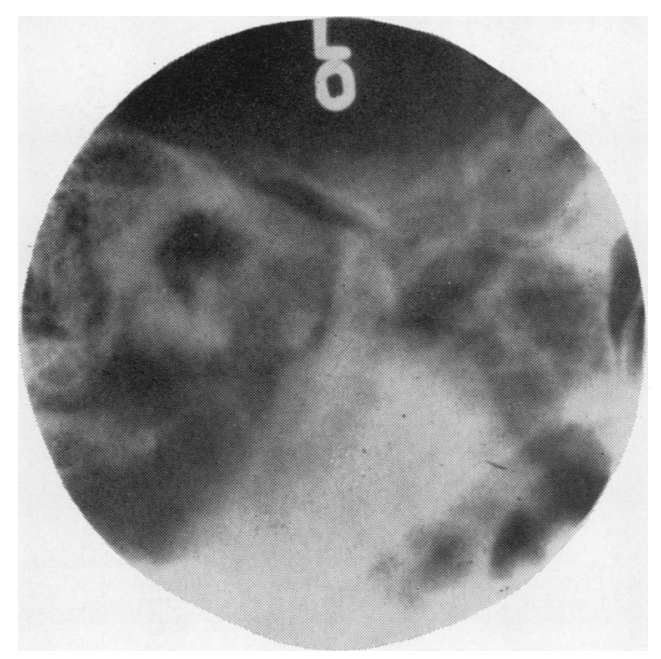

Fig. 8.-Case 2. Left temporomandibular joint in open position, showing erosion of anterior and superior aspects of mandibular condyle and flattening of temporal fossa.

of her fist. She was to do this three times daily, before each meal. This technique acts reflexly to relax the masseter and medial pterygoid muscles. Within 4 weeks, the maximum mandibular opening was increased by $11 \mathrm{~mm}$. to $44 \mathrm{~mm}$. Only the straight protrusive movement remained restricted, probably because of the destruction of the tendinous insertion of the lateral pterygoid muscles.

Once the range and character of mandibular movements improved, reduction of the occlusal surfaces of the posterior teeth was begun. Enamel was removed and underlying dentin was exposed. This necessitated tooth restoration by means of gold crowns. The patient was much more comfortable with her congruous bite, and establishment of a normal diet followed. With a reduction in tooth height, the soft tissues of the chin were realigned over the bony tissue to their natural position. The patient was no longer required to stretch her lower lip upwards excessively to make contact with the upper lip.

During the reduction in tooth height, the patient was instructed in a method of preventing tongue thrusting. This resulted in an improvement in speech, with complete elimination of the lisp (Jann, Whitman, and Jann, 1966).

The upper six anterior teeth were moved with a simple orthodontic appliance, which closed the gap between the upper and lower teeth.

\section{Temporomandibular Joints in Rheumatoid Arthritis}

The earliest changes occur in the synovial membrane, which becomes hyperaemic and infiltrated with lymphocytes and plasma cells. There is a thickening of the membrane and fluid accumulation in the joint cavity. Examination reveals swollen and tender temporomandibular joints. Pain and muscle spasm may limit joint movement. No radiographic changes may be discernible (Grokoest and Schwartz, 1959).

When the course of the temporomandibular-joint involvement is progressive, cartilage and bone become eroded. Adhesions may form between the synovial membrane and the capsular ligament. There is a characteristic flattening of the anterior surface of the mandibular condyle due to destruction of the fibrocartilage and denuded bone. Erosion of the ligamentous attachment of the lateral pterygoid muscle occurs in conjunction with the cartilaginous and bony tissue changes (Blackwood, 1963).

Degenerative joint disease may be superimposed on the rheumatoid arthritis. The anterior surface may develop a spur which is characteristic of degenerative joint disease (Schwartz and Marbach, 1965). This area becomes the site of new bone formation by a process of vascular invasion of the cartilage. Adhesions of the soft tissue may occupy the joint space and ultimately result in fibrous ankylosis.

The most characteristic change observable in radiographs of the temporomandibular joint in rheumatoid arthritis is the flattening of the anterior aspect of the condylar head. This is seen as a ragged outline of the cortical and subcortical bone. The subcortical erosions may appear as a radiolucency within the head of the condyle. In normal joints, the anterior movement of the condyle is readily seen in a radiograph as the patient opens his mouth. In rheumatoid arthritis, however, there is little difference in the position of the temporomandibular joints with the mouth open and with the mouth closed.

Clinical Signs and Symptoms.-An early sign may be a malocclusion characterized by an opening between the anterior teeth when the molar teeth are in contact. This opening may occur for two reasons: the destruction of the anterior and superior aspects of the mandibular condyle with disruption of lateral pterygoid function; and flexion contracture of the muscles of mastication, primarily the masseter and medial pterygoid muscles. These large elevator muscles of the mandible - the temporalis, masseter, and medial pterygoid muscles-pull the mandible upward and forward.

When flexion contracture occurs in these muscles, the primary site of pressure is just on those surfaces of the mandibular condyle that are seen to be eroded in the roentgenograms and histological sections from patients with rheumatoid arthritis. The eroded surfaces are the anterior and superior surfaces. If destruction of the condyle or flexion contracture is 


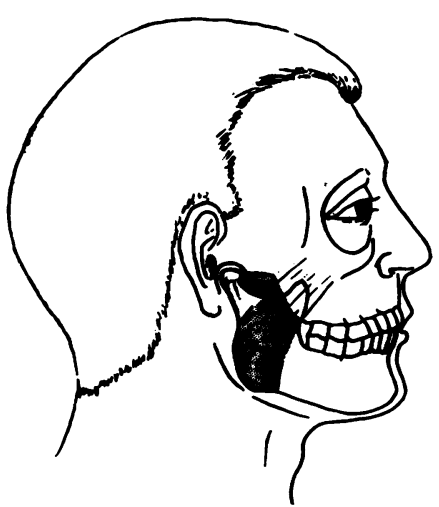

Fig. 9A.-Normal relationship of mandibular condyle to interior auditory canal and temporal fossa. The masseter and lateral pterygoid muscles are shown in part.

absent, the teeth would prevent the open bite. But in the presence of both phenomena, the molar teeth act as an axis on which the mandible rotates (Fig. 9).

Once an opening appears between the front teeth, the patient may increase the opening by thrusting his tongue into the space. He does this unconsciously in an attempt to reestablish an anterior seal while swallowing. (A conscious effort must be made to keep the tongue from darting forward while swallowing when the anterior teeth are parted.) This opening causes a frontal or lingual lisp (Van Riper, 1954). To allow contact of the upper and lower lips, they are constantly stretched, and this lengthens the mentalis and depressor labii inferioris muscles. The result is an upward migration of the point of the chin that normally overlies the bony gnathion. This chin displacement, with its accompanying effect on

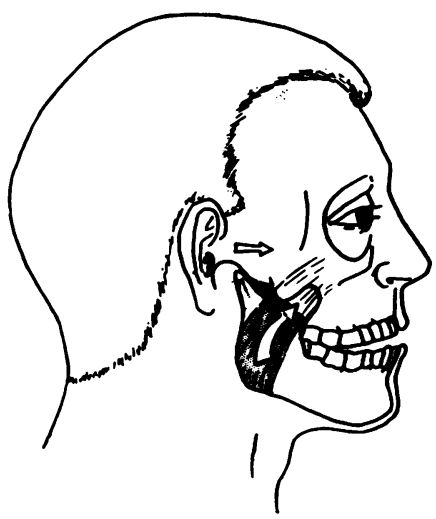

Fig. 9B.-The mandibular condyle is destroyed in characteristic fashion. Upper arrow shows direction of contraction of lateral pterygoid muscle and lower arrow that of masseter muscle. This results in the characteristic open bite.

the patient's appearance, is often his chief complaint, and it may be the primary reason for the patient seeking care.

\section{Summary}

The histology, radiography, and clinical signs and symptoms of rheumatoid arthritis of the temporomandibular joint are discussed, and two illustrative case histories are presented. In the first case the signs and symptoms associated with the temporomandibular joints were but one aspect of a polyarthritis. In the second case they were the major manifestation of the disease. Treatment was followed by improvement of mastication, and a reversal of the progressive facial deformity. In both cases, these improvements resulted in a greater sense of well being.

\section{REFERENCES}

Blackwood, H. J. J. (1963). Brit. dent. J., 115, 317 (Arthritis of the mandibular joint).

Einaudi, G., and Viara, M. (1964). Reumatismo, 16, 341 (Il comportamento dell' articolazione temporo-mandibolare nei pazienti affetti da artrite reumatoide).

Goodwill, C. J., and Steggles, B. G. (1966). Ann. rheum. Dis., 25, 133 (Destruction of the temporomandibular joints in rheumatoid arthritis).

Grokoest, A., and Schwartz, L. (1959). In Schwartz, L. "Disorders of the Temporomandibular Joint", p. 388. Saunders, Philadelphia and London.

Jann, G. R., Whitman, D. F., and Jann, H. W. (1966). J. Amer. dent. Ass., 73, 91 (Course to reeducate orthodontic patients in swallowing patterns).

Markowitz, H. A., and Gerry, R. G. (1950). Oral Surg., 3, 75 (Temporomandibular joint disease).

Ragan, C. (1949). J. Amer. med. Ass., 141, 124 (The general management of rheumatoid arthritis).

Russell, L. A., and Bayles, T. B. (1941). J. Amer. dent. Ass., 28, 533 (The temporomandibular joint in rheumatoid arthritis).

Schwartz L., and Marbach, J. J. (1965). J. Amer. Soc. Periodontists, 3, 184 (Changes in the temporomandibular joints with age).

Van Riper, C. (1954). "Speech Correction", 3rd ed., p. 260. Prentice-Hall, New York. 


\section{L'arthrite rhumatismale de l'articulation temporo-} maxillaire

\section{RÉSUMÉ}

On discute les symptômes et les signes cliniques, radiographiques et histologiques de l'atteinte temporomaxillaire au cours de l'arthrite rhumatismale. On présente deux observations pour illustrer ceci. Dans le premier cas les signes et les symptômes associés à l'atteinte temporo-maxillaire n'étaient qu'un des aspects d'une polyarthrite. Dans le deuxième cas ils étaient la manifestation majeure de la maladie. Le traitement entraîna une amélioration de la mastication et une régression de la déformation faciale. Dans les deux cas l'amélioration se traduisit par une plus grande sensation de bien-être.
$\mathrm{La}$ artritis reumatoide de la articulación temporomandibular

\section{SUMARIO}

Se discute la sintomatología clínica, histológica y radiográfica de la artritis reumatoide de la articulación temporo-mandibular. Se describen dos casos ilustrativos. En el primer caso los síntomas asociados con las articulaciones temporo-mandibulares representaron sólo un aspecto de una poliartritis. En el segundo caso estos síntomas fueron la mayor manifestación de la enfermedad. El tratamiento fué seguido de una mejoría de la masticación y de la deformación de la cara. En ambos casos esta mejoría trajo a los enfermos una sensación de bienestar. 